Review on Agriculture and Rural Development 2019 vol. 8 (1-2) ISSN $2677-0792$

\title{
EFFECT OF MANNANOLIGOSACCHARIDE (MOS) AND INULINSUPPLEMENTATIONONTHE PERFORMANCE OF CALVES REARED ON MILK REPLACER
}

\author{
SZANDRA TóTH \\ University of Kaposvár, Faculty of Agricultural and Enviromental 7400 Kaposvár \\ tothszandra8@gmail.com
}

\begin{abstract}
The objective of the current study was to examine the effects of mannan-oligosaccharides or inulin on HF dairy heifers' starter feed intake and daily weight gain in farm situations. We measured these parameters across two experiments. In Trial 1 (T1), next to the control group, 15-15 HF heifers received MOS or inulin supplementation from $1^{\text {st }}$ day of age to weaning. The amount of the supplementations changed according the calves' age and the amount of milk replacer from $12 \mathrm{~g}$ to $24 \mathrm{~g} /$ calf/day. We measured the individual feed intake daily, the live weight at $0,14,21$ and 60 days. In the second experiment (T2) we used $30 \mathrm{HF}$ heifers also in three group (Control, MOS, Inulin) but we gave more from the experiment materials $(28 \mathrm{~g} / \mathrm{calf} / \mathrm{day}$ MOS or Inulin). We started dosing the supplements with the colostrums feeding, and gave up on $14^{\text {th }}$ day of age. We also measured the individual feed intake daily and the live body weight (BW) at $0,14,28,42$ and 56 days. The treatments in T1 did not cause significant differences in average feed intake, body weight and average daily weight gain. When the calves got the supplementation with colostrum too, the ADWG was significant lower in the group fed inulin than control and group fed MOS $(\mathrm{P}<0.05)$. We calculate the ADWG all of the experimental periods. From 0 to 14 day, and from 0 to 56 day the ADWG in inulin group was lower than control group, but the datas of group MOS did not differ from the others. Due to the distribution of the birth weights, the lower ADWG did not manifest in differences in body weight in other points of the experiments. We did not find an interaction between the treatments and the daily feed intake of calves. According with our measurements, the colostrum supplemented with inulin can be able to reduce ADWG while not affecting to the appetite.
\end{abstract}

Keywords: Mannanoligosaccharide, Inulin, dairy calves, Feed intake, Daily weight gain

\section{INTRODUCTION}

The use of antibiotics for growth promotion purposes, increases the risk of development of antibiotic-resistant bacterial strains and the appearance of drug residues in foods (SILVA ET AL. 2012). According to FRANKLIN ET AL. (2005), there is a need for alternative products that can ensure production, health protection and economic efficiency similar to that provided by antibiotics. Promotion of the performance of farm animals is based on optimal functioning of the digestive system, in which eubiosis of the gastrointestinal tract plays an important role. Prebiotics can be a solution to prevent digestive tract diseases and thereby improve animal performance. Of the dietary fibres, fructan (a polymer of fructose molecules) supports the growth of beneficial bacteria in the intestine. The best known fructan is inulin, which is naturally present in more than 36,000 plant species. MASANETZ ET AL. $(2010,2011)$ found that $2 \%$ inulin supplementation increased the average daily weight gain (ADWG) and slightly improved the feed conversion ratio, while KRóL's (2011) research suggests that 3-6 g of inulin supplementation does not cause any change in feed intake and weight gain.

Mannanoligosaccharide (MOS) is a glucomannan-protein complex derived from the cell wall of yeast (Saccharomyces cerevisiae), which resists the action of digestive enzymes.MOS has excellent bacterium-binding properties. Supplementation of different doses of MOS ( 1 to $10 \mathrm{~g} / \mathrm{d}$ ) was reported to result in significantly increased feed intake (HEINRICHS et al. 2003, $\mathrm{P}<0.05$; MoRRISON et al. 2010, $\mathrm{P}<0.01$; GHOSH AND MEHLA. 2012 $\mathrm{P}<0.01$ ).GHOSH and MeHLA. (2012) and KRÓL (2011) observed a statistically significant 
increase in BWG.

The objective of the current study was to compare the effect of different supply and amount of MOS or inulin on starter feed intake and body weight gain in real farm situation.

\section{MATERIAL AND METHOD}

A total of $75 \mathrm{HF}$ calves (birth weight: $38.7 \pm 3.67 \mathrm{~kg}$ ) were included in the study within 2 trails. In every trial the heifers were divide into 3 equal groups (control, MOS, inulin) at time of birth (45 heifer in Trial 1 and 30 heifer in Trial 2). The calves received colostrum via an oesophageal tube within $2 \mathrm{~h}$ of birth only one time. The calves were took to individual hutches (Calf-Tel Pro II, Hampel Corporation, Germantown, Wisconsin, USA) after 12 to $24 \mathrm{~h}$ of birth. The calves had access ad libitum to fresh water from day 1 and calf starters (UBM Feed Ltd., Hungary) from $7^{\text {th }}$ days.In Trial 1, in the experimental groups (MOS, inulin) got the supplements into the liquid feed from day 1 until we stopped the liquid feeding. While in Trial 2, the calves got the supplementation with the colostrums and with the liquid feed until d 14. The liquid feeding protocols and the amount of the supplements are shown in Table 1 . In T1 the consumed milk replacer contain $21 \%$ crude protein and $17,5 \%$ fat level and were used with 14,5\% dilution ratio, while in T2 we used another milk replacer with $27 \%$ crude protein and $17 \%$ fat level with $14 \%$ dilution ratio.

Tables 1. Liquid feeding schedule and the amounts of the additives.

\begin{tabular}{ccc|ccc} 
& T1 & \multicolumn{3}{|c}{ T2 } \\
\hline day & liter/ day & $\begin{array}{c}\text { amount of } \\
\text { supplement } \\
\text { g/day }\end{array}$ & day & liter/ day & $\begin{array}{c}\text { amount of } \\
\text { supplement } \\
\text { g/day }\end{array}$ \\
\hline $\begin{array}{c}\text { 0 day, } \\
\text { colostrum }\end{array}$ & 3 & 0 & $\begin{array}{c}0 \text { day, } \\
\text { colostrum }\end{array}$ & 4 & 28 \\
$1-14$ & 5 & 12 & $1-4$ & 6 & 28 \\
$15-21$ & 7 & 12 & $4-14$ & 8 & 28 \\
$22-49$ & 9 & 24 & $15-49$ & 8 & 0 \\
$50-56$ & 4 & 12 & $50-53$ & 6 & 0 \\
\end{tabular}

Individual starter feed intake was recorded daily for all animals. The calves were weighed at the time of their birth and then on d 14 and 60 in Trial 1, and on d 14, 56 in Trial 2. From these body weight data we calculated the individual body weight gains for the given periods. Statistical analysis was done using the R Commander 3.4.1 program type (Free Software Foundation Inc, 1991). Arithmetic means, standard deviation (SD) were calculated using descriptive statistical procedures. One-Way ANOVA procedures of the programme were use for analysing and compare the variances of feed intake on average weekly consumption. Differences were considered as significant if $\mathrm{P}<0.05$. The recorded data on BW, ADWG variables were analysed using Repeated Measures Analysis of Variation and Tukey-Kramer multiple comparisons test were used to compare the differences between the results and to evaluate the significances of means between the different treatment groups of calves. 


\section{RESULTS}

To compare the starter feed intake, we calculated an average weekly consumption in each group. These datas summarised in Table 2. Contrary to preliminary studies, none of the prebiotics in our study increased the starter feed consumption.

Table 2. Average starter diet intake of calves at different ages (g/day), mean $\pm \mathrm{SD}$

\begin{tabular}{c|ccc|ccc} 
& \multicolumn{3}{|c|}{ T1 } & \multicolumn{3}{c}{ T2 } \\
\hline $\begin{array}{c}\text { Age } \\
\text { (days) }\end{array}$ & Control & MOS & Inulin & Control & MOS & Inulin \\
\hline $8-14$ & $53 \pm 19$ & $40 \pm 12$ & $54 \pm 15$ & $33 \pm 23$ & $25 \pm 21$ & $36 \pm 33$ \\
$15-21$ & $101 \pm 40$ & $69 \pm 30$ & $70 \pm 19$ & $150 \pm 81$ & $131 \pm 55$ & $164 \pm 103$ \\
$22-28$ & $98 \pm 26$ & $78 \pm 21$ & $92 \pm 20$ & $299 \pm 126$ & $338 \pm 157$ & $334 \pm 154$ \\
$29-35$ & $147 \pm 20$ & $144 \pm 25$ & $126 \pm 20$ & $510 \pm 153$ & $516 \pm 233$ & $484 \pm 314$ \\
$36-42$ & $190 \pm 17$ & $140 \pm 38$ & $180 \pm 25$ & $846 \pm 224$ & $899 \pm 263$ & $700 \pm 295$ \\
$43-49$ & $227 \pm 55$ & $251 \pm 49$ & $250 \pm 54$ & $1138 \pm 297$ & $1178 \pm 334$ & $1024 \pm 277$ \\
$50-56$ & $754 \pm 368$ & $603 \pm 286$ & $660 \pm 329$ & $1697 \pm 417$ & $1842 \pm 327$ & $1404 \pm 431$ \\
$57-63$ & $1818 \pm 548$ & $1690 \pm 35$ & $1790 \pm 421$ & $2726 \pm 366$ & $2813 \pm 282$ & $2448 \pm 355$ \\
\hline
\end{tabular}

Contrary to the literature (Gosh AND MEHLA, 2012; KRÓL 2011) we did not find statistically significant differences between the control and the MOS supplemented groups in BW and ADWG either. MASANETZ ET AL. $(2010,2011)$ reports on the increase in ADWG, caused by MOS, but this statement are not supported by our data in T1 and T2 neither. $28 \mathrm{~g}$ inulin given with colostrum can modify negatively the ADWG (Table 3.). This statement contradicts with previous studies in literature because none of the studies which examined the inulin effects on calves report about negative effects (MASANETZ ET AL. 2010, 2011; KRÓL, 2011). In pigs fed with 3\% inulin, BRAMBILLASCA ET AL. (2015) reported deterioration in feed efficiency and $\mathrm{N}$ retention. In $\mathrm{T} 2$, the measurements affected by inulin supplementation statistically differ from control group $(\mathrm{P}<0.05)$, and it slightly differ from MOS supplemented group too $(\mathrm{P}<0.1)$. Due to the distribution of the birth weights, the lower ADWG did not manifest in differences in body weight in other points of the experiments. Although, the Repeated Measures Analysis of Variation test shown that the $\mathrm{BW}$ and ADWG changes with time are statistically differ in groups $(\mathrm{P}<0.01)$ in $\mathrm{T} 2$.

\begin{tabular}{c|ccc|ccc}
$\begin{array}{c}\text { Table 3. Body weight (kg) and averagedailyweightgain (g/day) ingroups (mean } \pm \text { SD) } \\
\text { age of } \\
\text { weighing } \\
\text { (day) }\end{array}$ & & T1 & & & & \\
& & & & & & \\
\hline BW & Control & MOS & Inulin & Control & MOS & Inulin \\
\hline 0. & $39.5 \pm 4.2$ & $39 \pm 2.7$ & $38.8 \pm 3.9$ & $36.22 \pm 4.32$ & $39.00 \pm 3.4$ & $39.11 \pm 3.26$ \\
14. & $44.9 \pm 3.4$ & $43.6 \pm 4.4$ & $43.5 \pm 2.7$ & $42.11 \pm 5.47$ & $42.8 \pm 6.30$ & $41.11 \pm 3.79$ \\
56. & & & & $79.56 \pm 8.53$ & $81.9 \pm 6.36$ & $75.56 \pm 6.60$ \\
60. & $77 \pm 8.6$ & $77.4 \pm 7.1$ & $75.6 \pm 3.72$ & & & \\
\hline ADWG & Control & MOS & Inulin & Control & MOS & Inulin \\
\hline $0-14$ & $380 \pm 200$ & $320 \pm 210$ & $320 \pm 210$ & $421 \pm 297^{\mathbf{a}}$ & $383 \pm 193^{\text {ab }}$ & $140 \pm 198^{\mathbf{b}}$ \\
$0-56$ & & & & $776 \pm 129^{\mathbf{a}}$ & $761 \pm 69^{\text {ab }}$ & $647 \pm 106^{\mathbf{b}}$ \\
$0-60$ & $620 \pm 110$ & $630 \pm 120$ & $600 \pm 80$ & & & \\
\hline
\end{tabular}

Different letters indicate significant difference between groups. a,b $(\mathrm{P}<0.05)$ 


\section{CONCLUSIONS}

According to our studies, neither MOS nor inulin increases the starter feed intake for calves, regardless of the stage of calf rearing. 24 and $28 \mathrm{~g} /$ day MOS supplementation do not modify the body weight and average daily weight gain of calves. This finding is also true for $24 \mathrm{~g}$ non-colostrum inulin supplementation. $28 \mathrm{~g}$ inulin can decrease the ADWG if it given to the calves with the colostrum. As this amount $(28 \mathrm{~g})$ of inulin exceeds the amounts studied in the literature studies, it is possible that inulin has an upper limit for its applicability at an early age in dairy calves. Further studies are needed to discuss this position.

\section{REFERENCES}

Brambillasca, S., Zunino, P., CAJARVille, C. (2015): Addition of inulin, alfalfa and citrus pulp in diets for piglets: influence on nutritional and faecal parameters, intestinal organs, and colonic fermentation and bacterial populations. Livestock Science 178: 243250 .

Franklin, S.T., Newman, M.C., Newman, K.E., MeeK, K.I. (2005): Immune parameters of dry cows fed mannanoligosaccharide and subsequent transfer of immunity to calves. Journal of Dairy Science 88: 2. 766-775

GHOSH, S., MeHLA, R.K. (2012): Influence of dietary supplementation of prebiotics (mannanoligosaccharide) on the performance of crossbred calves. Tropical Animal Health and Production 44: 617-622.

HeINRICHS, A.J., JONES, C.M., HEINRICHS, B.S. (2003): Effects of mannanoligosaccharide or antibiotics in neonatal diets on health and growth of dairy calves. Journal of Dairy Science 86: 4064-4069.

KRÓL, B. (2011): Effect of mannanoligosaccharides, inulin and yeast nucleotides added to calf milk replacers on rumen microflora, level of serum immunglobulin and health condition of calves. Electrical Journal of Polish Agricultural Universities. 2: 14.

Masanetz, S., Wimmer, N., Plitzner, C., Limbeck, E., Preibinger, W., Pfaffl, M.W. (2010): Effects of inulin and lactulose on the intestinal morphology of calves. Animal 4:5: 739-744

Masanetz, S., Preibinger, W., Meyer, H.H.D., Pfaffl, M.W. (2011): Effects of the prebiotics inulin and lactulose on intestinal immunology and hematology of preruminant calves. Animal 5:7: 1099-1106

MORRISON, S.J., DAWSON, S., CARSON, A.F. (2010): The effects of mannanoligosaccharide and Streptococcus faecium addition to milkreplacer on calf health and performance. Livestock Science 131:2-3: 292-296.

Silva, J.T., BITTAR, C.M.M., FERREIRA, L.S. (2012): Evaluation of mannanoligosaccharides offered in milk replacers or calf starters and their effect on performance and rumen development of dairy calves. Brazilian Journal of Animal Science 41:3: 746752. 